Article

\title{
Three-Dimensional Urban Expansion Analysis of Valley-Type Cities: A Case Study of Chengguan District, Lanzhou, China
}

\author{
Sijia He ${ }^{1}$, Xiaoyun Wang ${ }^{1}$, Jingru Dong ${ }^{1}$, Baocheng Wei ${ }^{1}$, Hanming Duan ${ }^{1}$, Jizong Jiao ${ }^{1, *}$ and \\ Yaowen $\mathrm{Xie}^{1,2, *}$ \\ 1 College of Earth and Environmental Sciences, Lanzhou University, No. 222, Tianshui South Road, \\ Chengguan District, Lanzhou 730000, China; hesj17@lzu.edu.cn (S.H.); xyw@lzu.edu.cn (X.W.); \\ dongjingru2012@163.com (J.D.); 18804885115@126.com (B.W.); hanmingduan333@163.com (H.D.) \\ 2 Key Laboratory of Western China's Environmental systems (Ministry of Education), Lanzhou University, \\ No. 222, Tianshui South Road, Chengguan District, Lanzhou 730000, China \\ * Correspondence: jiaojz@lzu.edu.cn (J.J.); xieyw@lzu.edu.cn (Y.X.); Tel.: +86-138-9318-2834 (Y.X.)
}

Received: 20 July 2019; Accepted: 11 October 2019; Published: 14 October 2019

\begin{abstract}
The development of cities in the vertical dimension is important in valley-type cities where physical growth is limited by terrain. However, little research has focused on three-dimensional urban expansion of valley-type cities. Lanzhou is a typical valley-type city in China and Chengguan District is the core area of Lanzhou City. This research is aimed at understanding the development of valley-type cities through the analysis of the three-dimensional urban expansion of Lanzhou Chengguan District and providing a reference for urban planning. We extracted five periods of architectural contours and height information between 1975 to 2018 with the support of multi-source remote sensing and network data. We used overlay analysis and mathematical statistical methods to analyze urban horizontal expansion and used the building density, floor area ratio, vertical expansion speed, fluctuation degree, and skyline to analyze urban vertical expansion. We found that the mode of horizontal expansion of Chengguan District shifted from adjacency to enclave through mountain area reclamation. The area with the fastest vertical expansion speed first appeared in the horizontal expansion completed area, and then in both the rapid horizontal expansion area and in the horizontal expansion completed area. Before 2007, the speed of horizontal expansion increased and reached its peak while the vertical expansion speed was relatively stable. After that, the former decreased, and the vertical expansion increased rapidly and dominated the urban development. The vertical expansion of the valley-type city gradually dominates urban development. Urban planning should consider the three-dimensional expansion, especially in the vertical dimension.
\end{abstract}

Keywords: valley-type city; three-dimensional urban expansion; vertical urban expansion; Lanzhou Chengguan District

\section{Introduction}

Cities are where humans have the strongest effect on the natural environment [1]. Early urban sprawl tended to encroach on suburban in horizontal direction [2], under the pressure of rapid population growth, with many negative effects on society and the environment $[3,4]$, such as biodiversity loss [5], air pollution [6], and urban heat islands [7,8]. Rapidly growing cities are gradually improving land use efficiency with increasing building height in vertically to control urban outward sprawl [9]. It is more common in Asian countries with high population density to build many middle- and high-rise buildings [10]. Not only for metropolis with developed economies, vertically expansion is also important for relatively large cities of space-restricted, such as valley-type cities, as it 
is difficult to expand outward constantly. As an essential aspect of urban expansion, vertical expansion is the embodiment of urban compactness, economy, population growth, and residential lifestyle [11]. However, vertical expansion also contributes to "urban diseases" [12,13], such as overcrowding, traffic congestion, pollution, and ventilation obstacle. Therefore, an in-depth understanding of the process of urban time-space expansion and change in three-dimension (both in horizontal and vertical direction) is fundamental for rational planning and efficient use of urban space to sustainable development [14].

Traditional urban expansion research pays more attention to horizontal expansion and ignores vertical expansion [15-17]. With the support of remote sensing, urban three-dimensional information extraction technology have been developed, and some methods or parameters have been applied to study the three-dimensional (3D) expansion in recent years. For example, Zambon et al. [18] acquired official statistics building data in each Greek municipality and proposed the "Vertical-to-Horizontal Growth" ratio to discriminate intense vertical expansion and understand metropolitan transformations comprehensively. Zhang [19] used the monoplotting technique to extract building information and applied a series of indices to analyze architectural landscape in block of Qingdao. Zhang et al. [20,21] employed the SS-coMCRF model to obtain data from medium resolution Landsat image and adopted Gaussian kernel density, overlay analysis to find the different expansion pattern in East Asian megacities and relationships between major socioeconomic factors and urban 3D expansion in Guangzhou. Qin et al. [22] proposed the analysis of the 3D fractal dimension and found that the 3D space utilization of Yangzhou city became more efficient and intensive. There are also studies used radar [23,24] or laser data [25] to extract urban 3D information or presented new methods (e.g., volume [26] extent of urban expansion [27]) to elaborate the anisotropy and spatial heterogeneity of expansion as well as the spatial-temporal characteristics of urban 3D growth. However, the data previous studies used such as active or passive remote sensing data was often limited by expansive prices, difficult access methods, short time spans, and high processing technology. Medium resolution Landsat images are more suitable for studies of large metropolis. Therefore, it is necessary to utilize multi-source data in order to obtain long time series of high-precision urban three-dimensional data. Aerial photographs, historical topographic maps, and high-resolution images developed in recent years and network data or records have made it possible. For example, Zheng et al. [28] used GeoEye images and network data including building height and built year to obtain building footprints and their heights of the residential neighborhoods in Beijing from 1949 to 2009 for residential landscape change analysis. Besides, the analytical methods previous studies employed can only analyze the 3D expansion of entire city or block in terms of amount, but not spatially. Grid analysis can realize the spatialization of quantitative indicators; it also can provide more information than single building height. Such as Qin et al. [22] expressed the 3D morphology expansion with grid analysis and identified areas with the highest expansion intensity.

Some studies identified some patterns of the expansion process, for example, Frolking et al. [10] found that 100 cities around the world have expanded outwards and upwards, especially in East Asia, and Indian cities were more inclined to expand outwards. In contrast, built-up growth in Surabaya, Indonesia led to vertical rather than horizontal development [26]. Zhang et al. [21] found that three megacities in Central Asia were continuing to grow vertically, although they were at different urban development stages. They also found that cities usually tended to grow vertically in the already developed areas after ending their horizontal expansion. Similarly, findings in Shanghai and in Greece $[18,27]$ shows that, cities often alternate their expansion process between phases of horizontal growth and vertical growth. Other studies found that residential neighborhoods of Beijing form a "low-high" pattern from the urban central areas to the urban edges [28], and the districts architectural landscape differentiation in Qingdao is more consistent with their diverse development history, function, and planning [19]. Other studies simulated the process of urban expansion in Surrey, Canada, and Wuhan, China. Koziatek et al. [2] observed that in Surrey high-rise buildings will be more common near transportation networks, urban centers, and higher population densities, while He et al. [29] noted that in Wuhan the highest buildings will occur near the lake and undeveloped 
land. Existing 3D urban expansion studies intend to focus on megacities with high economic. Little information exists on valley-type cities restricted by space. Are there any special urban expansion patterns of these cities with limited spatial patterns? Are these cities entering a period of vertical expansion earlier than plain cities? Answers to these questions are important for understanding the development of these cities.

Therefore, to fill these gaps, the Chengguan District, a most important and most historical region of typical valley-type city Lanzhou in northwestern China, was chosen as the study area. Multi-source data such as aerial photographs, topographic maps, high-resolution images, and network data from year 1975 to 2018 were used to obtain long time spans, high-precision built-up area boundary, building footprints, and heights information. Grid analysis was applied to realize the spatialization of quantitative indicators (e.g., floor area ratio [19], vertical expansion speed [27], and fluctuation degree [30]). The overarching aim of this study is to analyze the urban 3D spatiotemporal expansion process features to provide a case for understanding the process of expansion of valley-type cities.

\section{Study Area}

Lanzhou is located in the geometric center of China's land area. As an important node in the northwestern region of China's "Silk Road Economic Belt", it has been an important transportation hub connecting the eastern part of China to the northwest region since ancient times. The terrain of Lanzhou City is special. The Yellow River flows out from the many canyons in the upper reaches, and the water flow slows down in the valley. The city is built in a dumbbell-shaped river valley formed by thousands of years of alluvial sedimentation. Lanzhou was an important military fortress in ancient China and is a major town for industrial development in modern China. Chengguan District was named after its location in the ancient city of Lanzhou since the Sui Dynasty. The ancient city was originally built in the dumbbell-shaped river valley eastern basin, that is, the south bank of the Yellow River in the southwest of present Chengguan District, and it has been used as a government center for the state, province or county for more than a thousand years. During the Ming dynasty, the ancient Lanzhou city in the Chengguan District expanded outwards and added an outer city wall, gradually forming an urban pattern of the "inner and outer city", which laid the scope of the core area of Lanzhou. When Lanzhou City was established in 1941, it was based on the ancient Lanzhou City of the Ming and Qing Dynasties. Therefore, Chengguan District has always been the core area and essence of Lanzhou City. The highest altitude of the two mountains in the north and south of Chengguan District of Lanzhou City reached $2138 \mathrm{~m}$, which is more than $600 \mathrm{~m}$ higher than the lowest valley elevation. The Yellow River flows through the city from west to east and streams through Chengguan District for $18 \mathrm{~km}$. In 2017, the total built-up area of Chengguan District was $73.92 \mathrm{~km}^{2}$, the GDP was 94.89 billion yuan, and the population was 1,136,100, accounting for nearly $20 \%, 40 \%$, and $40 \%$ of Lanzhou City, respectively, and the population density reached 17,804 people $/ \mathrm{km}^{2}$. Chengguan District has 26 blocks, including the Linxia Road block and Zhangye Road block (Figure 1), with a total of 155 communities. 


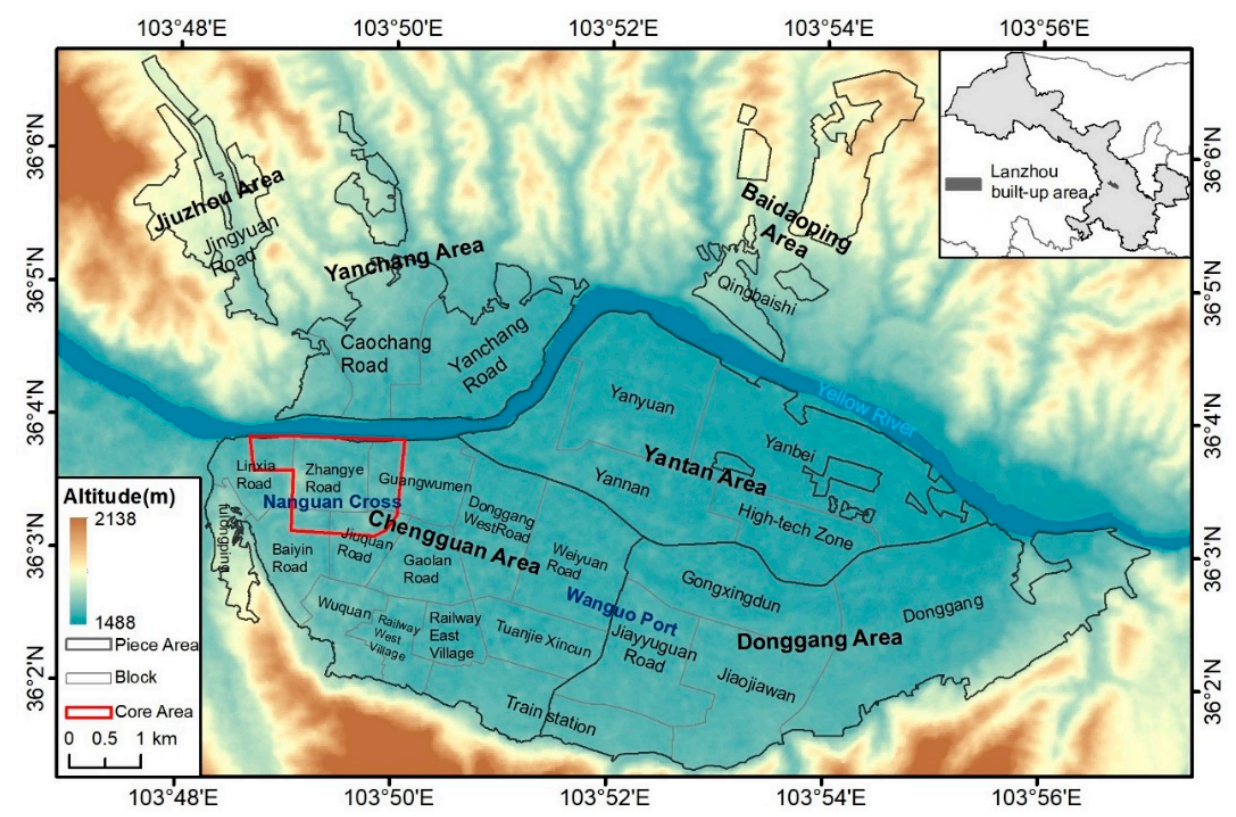

Figure 1. Overview of the study area.

\section{Materials and Methods}

\subsection{Data Sources and Extraction of the City Three-Dimensional Information}

In order to analyze the horizontal expansion of the city, the built-up area boundaries were extracted from the multi-source data. Depending on the availability, data came from year 1975, 1987, 1998, 2000, 2007, and 2018. Aerial data were used for 1975 (scale 1:40,000) and 1987 (scale 1:3800); topographic map data (scale 1:10,000) were used for 1998; Digital Orthophoto Map (DOM) data (resolution: $1 \mathrm{~m}$ ) were used as supporting data for 2000; and DOM data (resolution: $0.2 \mathrm{~m}$ ) and Gaofen-2 satellite image data (resolution: $1 \mathrm{~m}$ ) were used in 2007 and 2018, respectively. Due to the large number of aerial images and their high overlap, to reduce the computational workload we carried out thinning, splicing, and image registration processing of the first two periods of aerial data with ArcGIS10.5 and ENVI5.3. The overlap accuracy of the processed aerial images was 30\%-40\%, which met the needs of later aerial images correction. We also preprocessed the satellite image data with FLAASH atmospheric correction and radiation calibration provided by ENVI5.3. After establishing a boundary extraction criterion of urban built-up area based on the multi-source remote sensing data, we applied a visual interpretation method to digitize the built-up area boundaries in each period. Specifically, areas with buildings, well-established municipal infrastructure, and spatially contiguous areas were considered built-up areas, including development areas or new urban areas with important urban functions in the suburbs of the city, but excluding rural settlements surrounded by cultivated land.

Building height was used to analyze the vertical expansion of the city, and the first step was to obtain these data for year 2018. Data about building footprints and their floors information was obtained from "Baidu Map" data (map.baidu.com) for circa 2018. The built years and floors information was obtained from the real-estate sale website "Anjuke" (www.anjuke.com) [31]. We found that most of the footprints data was correct [28] by comparing them to the 2018 Gaofen-2 satellite images of the study area, but a considerable amount of floors information was missing. The remaining building footprints of the missing or non-updated areas were manually digitized from Gaofen-2 satellite images, and their floors number were found from "Anjuke" website data or counted with windows from satellite images by referring to Baidu Map Street View data. Since residential buildings represented the main building type of Chengguan District, building heights were estimated by multiplying the number of floors by $3 \mathrm{~m}$, according to the typical floor height defined in the residential building code [32]. Besides, heights of newly built shopping malls or office buildings were obtained from their official 
information. On this basis, building footprints and their heights data from the other five periods were obtained. Specifically, buildings that have not changed in each period were distinguished according to satellite images and their built years; the footprints of changed buildings were digitized from satellite images, aerial data, or other source data of each period by visual interpretation, and the number of floors were counted from Google historical maps or image data from each period, un-changed buildings for each period were used as controls, and then building heights were estimated.

Following the Code for Design of Civil Building [33], we classified the buildings into six types, low-rise, multi-story, middle-rise, small high-rise, high-rise, and ultra-high-rise, in which small high-rise and high-rise were decomposed from "High-rise buildings" of 30-100 m. The floors number and height of various types of buildings are shown in Table 1.

Table 1. Classification of the buildings in terms of building height.

\begin{tabular}{ccc}
\hline Classification & Floor & Height $(\mathbf{m})$ \\
\hline Low-rise building & $1-3$ & $\leq 9$ \\
Multi-story building & $4-6$ & $9-21$ \\
Middle-rise building & $7-9$ & $21-30$ \\
Small high-rise building & $10-16$ & $30-50$ \\
High-rise building & $17-40$ & $50-100$ \\
Ultra-high-rise building & $>40$ & $>100$ \\
\hline
\end{tabular}

\subsection{Analysis of Urban Expansion}

Many different methods or parameters were used to analyze the urban expansion in horizontal and vertical direction through time. First, overlay analysis and mathematical statistical methods (e.g., change rate of the built-up region in each period can be calculated through dividing the area subtracting result of built-up region between two adjacent period by the time difference of these two adjacent years.) were used to analyze the urban horizontal expansion with built-up area boundaries data. Then, building height and footprints information was used to analyze urban vertical expansion. Building density was used to analyze the spatial distribution changes of density of different heights buildings and floor area ratio was used to analyze the intensity of constructed land. The vertical expansion speed index was used to analyze urban vertical expansion speed changes and location of major changes. Skyline analysis and fluctuation degree were used to analyze the change of urban appearance. Floor area ratio, vertical expansion speed, and fluctuation degree were calculated by grid analysis in ArcGIS. First, we used the fishing net tool to create regular grids in the study area (through testing, the grid calculation unit size was determined to be $200 \mathrm{~m}$ ), and then used the field calculator to count base area and height of building in the grid and the other parameters.

\subsubsection{Building Density}

Non-parametric kernel density estimation (KDE) is usually used to estimate the probability density function of a sample, and some special aggregation information is found from its distribution. According to the probability theory, Scott [34] defines it as: set $\left(x_{1}, x_{2}, \ldots, x_{\mathrm{n}}\right)$ to be an independent and continuously distributed sample with the same distribution as the density function $\mathrm{f}$, then the kernel density estimate $\hat{f}_{h}(x)$ is:

$$
\hat{f}_{h}(x)=\frac{1}{n} \sum_{i=1}^{n} K_{n}\left(x-x_{i}\right)=\frac{1}{n h} \sum_{i=1}^{n} K\left(\frac{x-x_{i}}{h}\right) .
$$

Note: $K$ is a non-negative kernel function; $n$ is the sample size; and $h$ is the bandwidth; $x-x_{i}$ is the distance from the evaluation point $x$ to $x_{i}$.

This paper used the nuclear density analysis tool provided by ArcGIS. The principle was to set the search radius (bandwidth) to produce a smooth circular surface with the sample point as the center. 
The density value was estimated by the kernel density function, and the value decreased with the increase of the distance from the center of the circle, and decreased to zero when the distance reached the radius of circle. After multiple tests, we selected $300 \mathrm{~m}$ as the search radius.

\subsubsection{Floor Area Ratio}

The floor area ratio (FAR) [19] is an important index for measuring the intensity of constructed land and the comfort of human settlements. The calculation formula is:

$$
\mathrm{FAR}=\frac{\sum_{i=1}^{n}\left(h_{i} / C^{*} A_{i}\right)}{P} .
$$

Note: $A_{i}$ and $h_{i}$ are the base area and height of building $i$, respectively; $n$ is the number of buildings in the calculation unit; $C^{*}$ is constant $\left(C^{*}=3.0 \mathrm{~m}\right)$; and $P$ is the area of the calculation unit.

\subsubsection{Urban Vertical Expansion Speed}

The average annual growth of building volume is used to evaluate the vertical expansion speed (VES) of cities in different periods, calculated with Equation (3):

$$
\mathrm{VES}=\frac{\left(V_{j, t+m}-V_{j, t}\right)}{m} .
$$

Note: $V_{j, t+m}$ and $V_{j, t}$ are the sum of the volumes of the buildings in the $t+m$ and $t$ time calculation units, and $m$ is the given period (years).

\subsubsection{Fluctuation Degree}

The fluctuation degree (FD) is a regional urban spatial morphological factor, which can characterize the degree of dispersion of building height in the calculation unit [30]. It is often calculated as the ratio of the height standard deviation and the average height of the building in the calculation unit, as follows:

$$
\bar{H}=\frac{\sum_{i=1}^{n} A_{i} h_{i}}{\sum_{i=1}^{n} A_{i}} \mathrm{FD}=\frac{\sqrt{\sum_{i=1}^{n}\left(h_{i}-\bar{H}\right)^{2} / n}}{\bar{H}} .
$$

Note: $A_{i}$ and $h_{i}$ are the base area and height of the building $i$; and $\bar{H}$ and FD are the number of buildings, the weighted average height and fluctuation degree of buildings in the calculation unit, respectively.

\subsubsection{Skyline}

The skyline of the city is a representation of the overall image and pattern of the city [35]. In a narrow sense, skyline refers to the contour line formed by the city from a certain angle. In order to observe the change of the city outline from a side view of the city, we used ArcScene to stretch the height of the urban buildings and generate the silhouette of the city buildings in the background from the main axis and vertical axis of the city, which is in the S-N direction and in the W-E direction.

\section{Results}

\subsection{Horizontal Urban Expansion}

We overlaid the five periods of built-up area boundary data of the Chengguan District for 1975-2018 (Figure 2), and calculated the area of built-up region and its change rate in each period (Table 2). The results show that the horizontal expansion of Chengguan District was mainly along the original floodplain in the northeast direction, principally by adjacency expansion. Along with the development of the city's barren mountains, a pattern of enclave expansion gradually appeared. 
The speed of horizontal expansion first increased and then decreased. The speed of expansion was the fastest during the period 1998-2007. In 1975, the area of built-up region of Chengguan District was $25.6 \mathrm{~km}^{2}$, and most of the built-up area was concentrated in the southwest and the north of the Yanchang area across the river from the core area, with fewer built-up areas in the southeast. In $1975-1987$, the area of built-up region increased by $5.38 \mathrm{~km}^{2}$, with a low change rate $\left(0.45 \mathrm{~km}^{2} / \mathrm{a}\right)$. The main form of urban horizontal expansion was infill expansion, with a small number of adjacency extensions in the north and south. In 1987-1998, the area of built-up region increased by $9.54 \mathrm{~km}^{2}$, and its change rate increased $\left(0.87 \mathrm{~km}^{2} / \mathrm{a}\right)$. There were a small number of internal filler expansions in the southeast of the city. The adjacent horizontal expansion was more significant in the northeast direction of the city, the southern part of the Yanyuan block, and the western part of Yannan block. The city began to expand to the urban northwest Yellow River terrace, in the form of enclave expansion, which is a type where the expansion area is spatially separated from the built-up area but functionally connected. In 1998-2007, the area of built-up region increased by $9.45 \mathrm{~km}^{2}$, and its change rate peaked $\left(1.05 \mathrm{~km}^{2} / \mathrm{a}\right)$. The main form of urban horizontal growth was adjacent expansion, with the original floodplain in the northeastern as the principal direction. In 2007-2018, the area of built-up region increased by $8.72 \mathrm{~km}^{2}$, and its change rate decreased rapidly $\left(0.79 \mathrm{~km}^{2} / \mathrm{a}\right)$. The city expanded intensely to the northern mountain area, where the elevation reached more than $1800 \mathrm{~m}$, in the main form of enclave expansion. This shows that the demand of construction land in Chengguan District was rising gradually, which the plain in the Valley Basin could not meet the demand of urban development, and that urban construction extended far from the core area through enclaves.

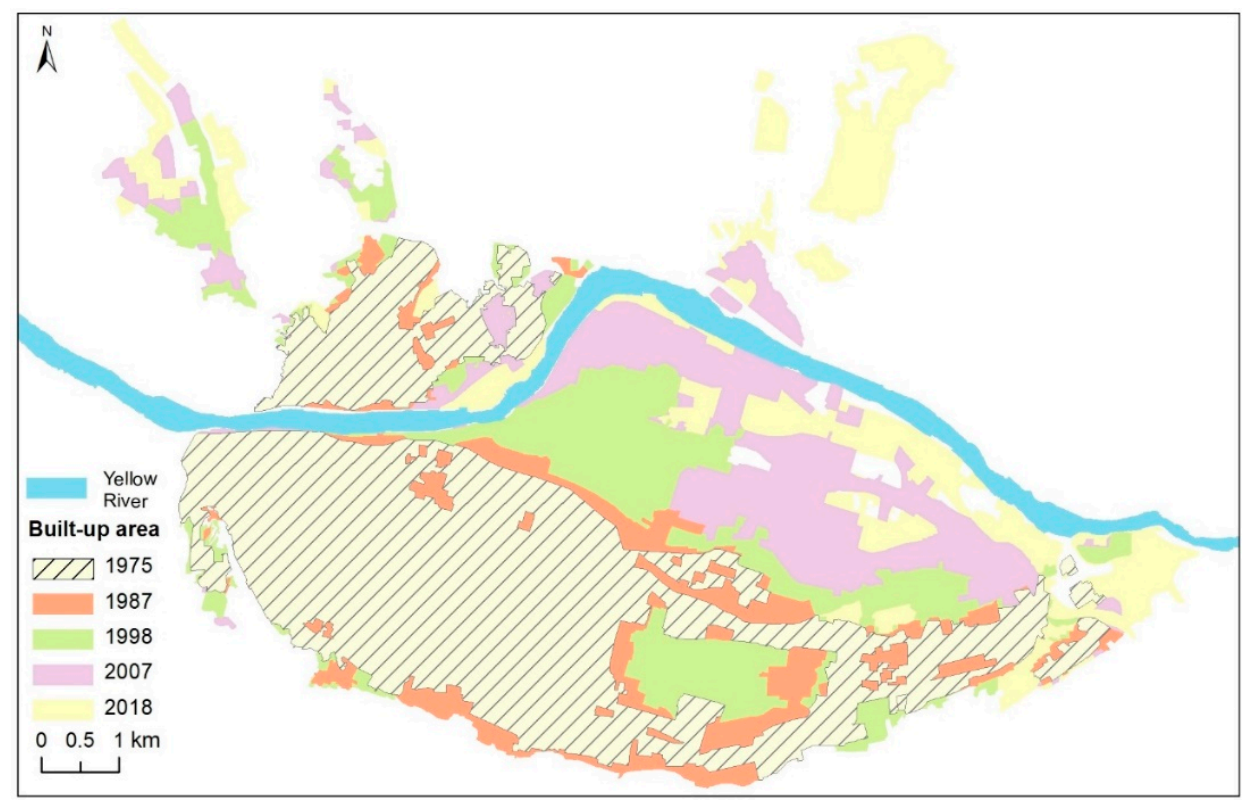

Figure 2. Expansion of the built-up area of Chengguan District from 1975 to 2018.

Table 2. Area and change rate of built area.

\begin{tabular}{cccccc}
\hline & 1975 & $\mathbf{1 9 8 7}$ & $\mathbf{1 9 9 8}$ & $\mathbf{2 0 0 7}$ & $\mathbf{2 0 1 8}$ \\
\hline Area $\left(\mathrm{km}^{2}\right)$ & 25.6 & 30.98 & 40.52 & 49.97 & 58.69 \\
Change rate $\left(\mathrm{km}^{2} / \mathrm{a}\right)$ & 0.45 & & 0.87 & 1.05 & 0.79 \\
\hline
\end{tabular}

\subsection{Vertical Urban Expansion}

\subsubsection{Changes in Building Height}

Through the method described in Section 3.1, we derived the building height model of Chengguan District for the five periods of analysis (Figure 3), and found that for more than 40 years, the 
city of Chengguan District had underwent strong vertical growth at the same time as it was expanding horizontally.

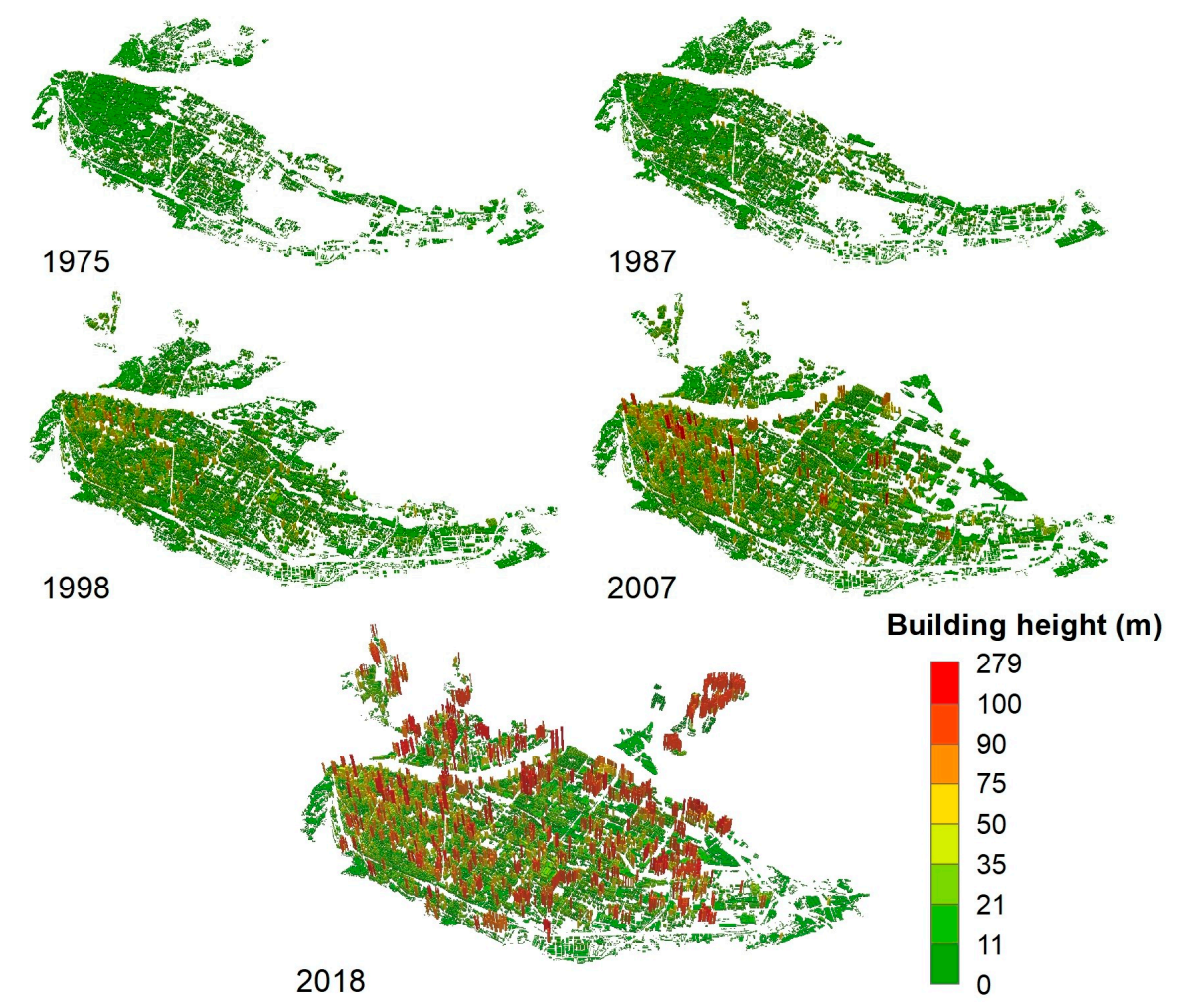

Figure 3. Three-dimensional building height of cities in different years.

In 1975, the buildings of Chengguan District were generally low. Higher buildings (11-21 m) were sporadically distributed around the core area and were more concentrated in the middle of the southern part of the built-up area-East of the Gaolan block, Guangwumen block, and Railway West Village block, west of the military airport.

In 1975-1987, higher buildings (11-21 m) increased in the core area and the Yanchang area, but their distribution was fragmented and sparse. In the middle of the southern built-up area, the buildings of 11-21 m height were centrally distributed and the range expands in the east-west direction, and higher buildings (21-35 $\mathrm{m}$ ) appeared.

In 1987-1998, a wide range of 21-35 m buildings and a small number of 35-75 $\mathrm{m}$ buildings emerged around the core area, forming a gathering centered on the Nanguan Cross. Development during this period added more new 11-21 m buildings in the former military airport area in the southeast of the built-up area, more new 3-11 m buildings in the northeast former Yellow River floodplain, and more new 11-35 $\mathrm{m}$ buildings in the northwest mountain platform area.

In 1998-2007, the gathering of higher buildings in the core area was expanded, and a large number of high-rise buildings of 35-75 $\mathrm{m}$ were added. The area of 21-35 $\mathrm{m}$ buildings in the Yanchang area and in the southeast of the built-up area expanded. The newly built buildings in the northeastern part of the built-up area were mainly 11-35 m buildings, and high-rise buildings of 50-90 m also begun to appear.

In 2007-2018, buildings of 35-75 $\mathrm{m}$ in core area increased and ultra-high-rise buildings over $100 \mathrm{~m}$ in the core area started to be sparsely distributed. Building communities of 35-100 $\mathrm{m}$ in other areas were developed rapidly, and became more concentrated along the Yellow River. The newly built buildings in the northeast platform of the built-up area were mainly $90-100 \mathrm{~m}$ buildings.

The above analysis shows that the building height of Chengguan District changed dramatically during the study period, showing an upward trend on the whole. In the early days, the urban 
construction in the periphery of the core area was high; in 1987-1998, the core areas began to be remodeled and gradually formed the Urban Development Center in the Nanguan Cross; in 2007-2018, the building height increased both in the core built-up area and, even faster, in the mountain terrace area.

Since multi-story and higher buildings have a greater impact on vertical urban expansion, we counted their numbers, areas, and volumes (Figure 4). It can be seen that the height of the buildings playing a leading role in urban expansion was increasing, the proportion of lower buildings was decreasing, and its change rate of area and volume was gradually decreasing. From 1975 to 1987, the newly added buildings were mainly multi-story buildings, with new multi-story and middle-rise buildings accounting for 78\% (1483) and 19.5\% (371) of newly added buildings, respectively. From 1987 to 1998 , the number of newly added mid-rise and high-rise buildings increased, with new multi-story and mid-rise buildings accounting for $49.5 \%$ (1446) and 40.3\% (1177), respectively. The growth rate in area and volume of mid-rise buildings significantly accelerated. From 1998 to 2007, the newly added buildings were mainly mid-rise buildings. The number of new multi-story buildings was significantly reduced, and the number of small high-rise and high-rise buildings increased. Newly added multi-story, mid-rise, small high-rise, and high-rise buildings accounted for $29.2 \%, 43.7 \%, 13.7 \%$, and $12.7 \%$, respectively. The increase rate in area and volume of multi-story and mid-rise buildings significantly slowed down. In 2007-2018, the newly added buildings were mainly high-rise buildings, ultra-high-rise buildings began to appear, and new high-rise and ultra-high-rise buildings accounted for $81.1 \%$ and $11.5 \%$, respectively. The rate of increase in the area and volume of high-rise buildings had rapidly increased, while that of multi-story and middle-rise buildings was significantly reduced. In particular, the growth rate of high-rise buildings was much larger than that of small high-rise buildings. This was associated with higher buildings having less floor space, so they were more efficient at meeting the growing needs of the population.
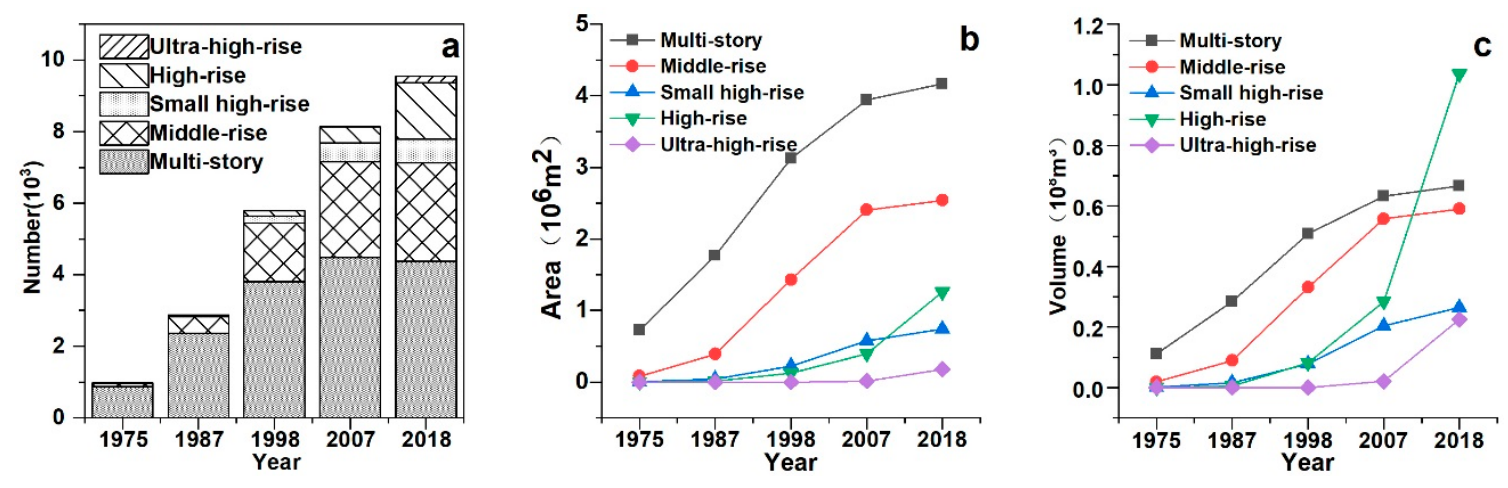

Figure 4. (a) Number, (b) area, and (c) volume change for each type of building.

\subsubsection{Building Density and Floor Area Rate Change}

Due to the small number (176 buildings in 2018) and the small density of ultra high-rise buildings, we calculated the nuclear density of multi-story and above buildings of different periods except for ultra-high-rise buildings, and the results are shown in Figure 5. In 1975, multi-story buildings were located in the west of Jiayuguan Road, in the southern part of the built-up area, and their density in the east of the core area to Jiayuguan block was relatively high. There were relatively few mid-rise buildings, and they were concentrated in the block of Gaolan Road. From 1975 to 1987, the multi-story building expanded to the Yanchangbao area, and its building density increased as a whole. The mid-rise buildings expanded toward the core area, and their density increased slowly. Small high-rise buildings appeared sporadically in the southwestern part of the built-up area. From 1987 to 1998, the multi-story and mid-rise buildings were expanded to the southeast of the built-up area. The density of multi-story buildings increased overall, and the density of mid-rise buildings in the core area and the south of the core area was relatively high. The density of small high-rise and high-rise buildings in the core area increased and their distribution were concentrated. From 1998 to 2007, multi-story and 
mid-rise buildings expanded to the northeast of Yantan area. The density of multi-story buildings was generally high, and the density of mid-rise buildings in the Yannan block area increased. Small high-rise and high-rise buildings had a high degree of expansion to the streets of Gaolan block, and their density was highest in the Jiuquan block and Nanguan Cross in the south of the core area. From 2007 to 2018, the scope of multi-story buildings changed little, and its density declined in the Tuanjie Xincun and Zhangye blocks. The range and density of mid-rise and small high-rise buildings had not changed much. Except for Yannan Street and Donggang block, the density of high-rise buildings in most areas of the built-up area had increased significantly, and their density was highest in the northeastern platform of the built-up area.

The change of FAR (Figure 6) shows that from 1975 to 2018, the building FAR increased with the three-dimensional expansion of the city, with the core area having the highest FAR. In 2007-2018, the Wanguo Port, located in Jiayuguan Road in the southeast of the built-up area, was densely built, so its FAR was very high. In addition, the large-scale construction of high-rise buildings had led to the emergence of high-FAR areas in 2018, and only individual grid areas had FAR values greater than 5 . In general, in order to ensure the comfort of human settlements, the FAR of high-rise buildings should not exceed 5, and the FAR of multi-story buildings should not exceed 3. In 2018, the FAR of most areas of Chengguan District was between 0-3, and the core area of the city was between 3-5. This shows that the level of human settlement comfort was overall higher in Chengguan District, while it was lower in the core area.

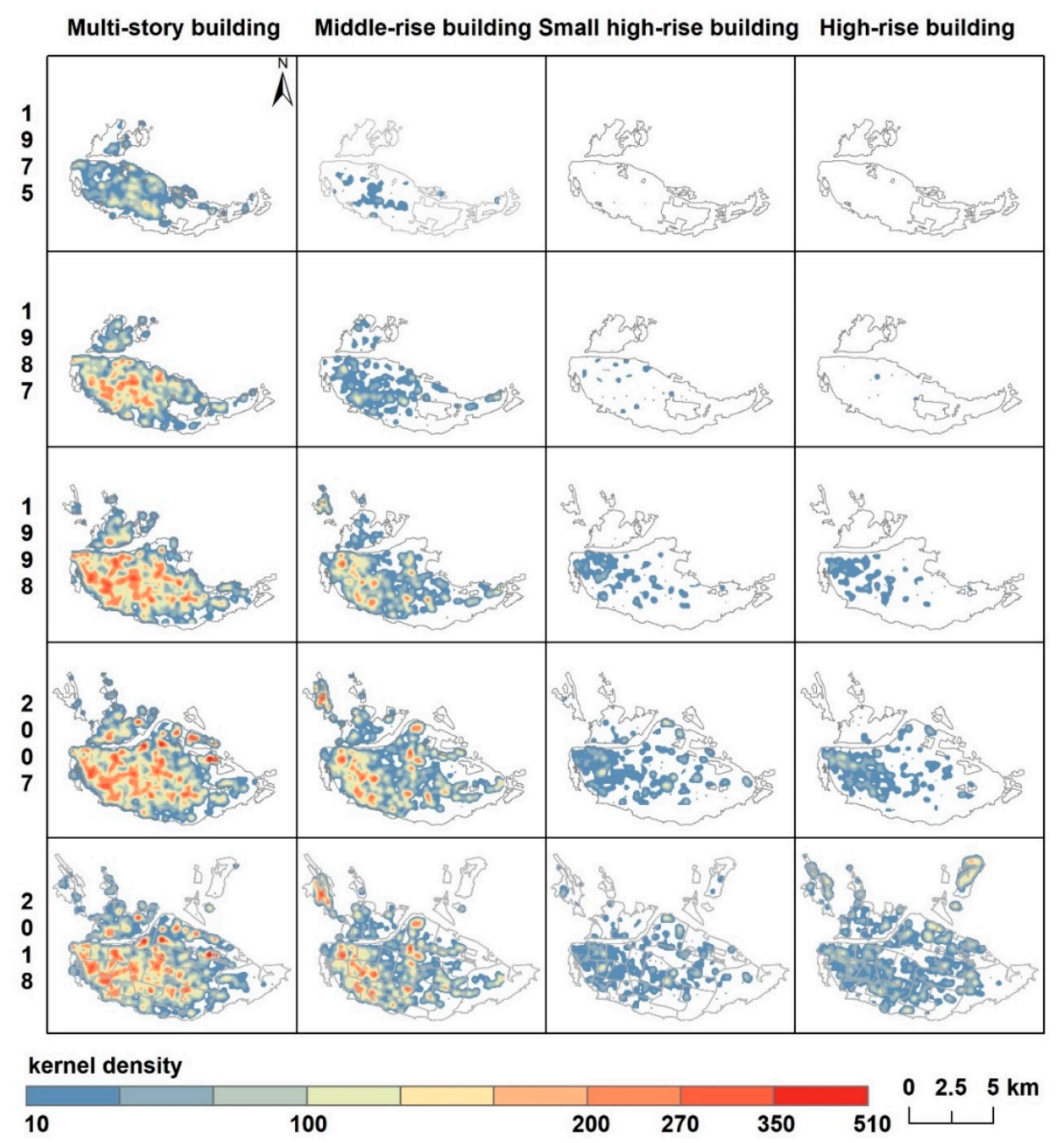

Figure 5. Nuclear density analysis of different types of buildings at different periods. 


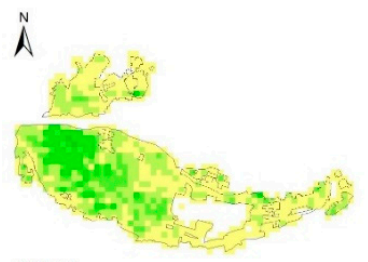

1975

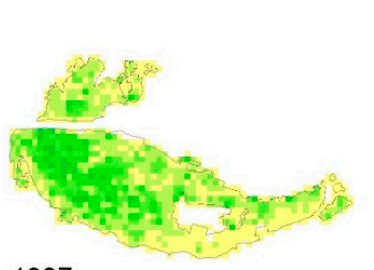

1987

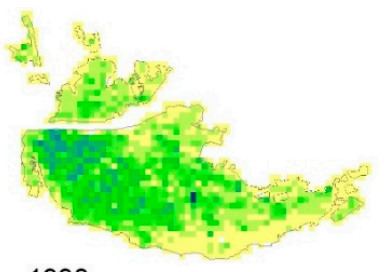

1998

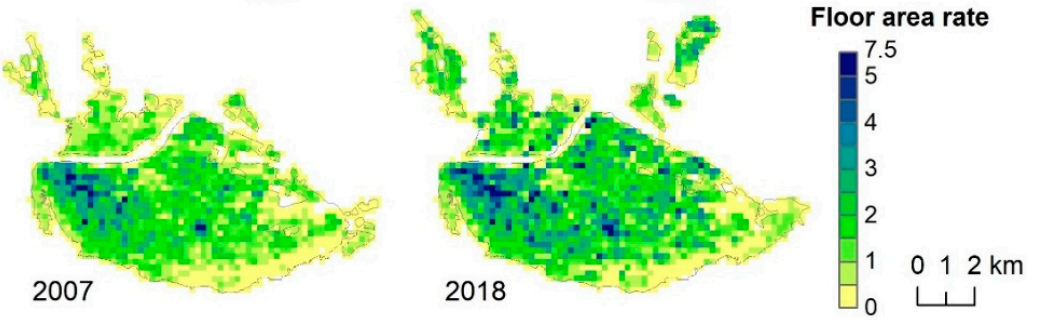

Figure 6. Building floor area rate change.

\subsubsection{Vertical Expansion Speed}

Using Formula (3) we calculated the building volume in each unit to map the speed of vertical expansion (Figure 7). We found that from 1987 to 1998, the vertical expansion of the Chengguan District occurred mostly in the urban core area where the horizontal expansion was complete. After 1998, vertical expansion often occurred violently with horizontal expansion, and still appeared in areas where horizontal expansion completed. From 1975 to 1987, the urban vertical expansion speed was low overall, and zero or negative expansion was caused by the presence of demolition and unfinished construction during the development process. From 1987 to 1998, the core area began to be vigorously reformed, the vertical expansion speed was accelerated, and the horizontal expansion occurred in the southeast and northeast, but the vertical expansion speed in the southeast was faster. From 1998 to 2007, the vertical expansion speed in the core area and the Yantan area northeast of built-up area increased significantly, and the vertical expansion speed in Yantan area was faster and wider. From 2007 to 2018, the northeastern platform area and most eastern part of the built-up area experienced dramatic vertical expansion. The vertical expansion was more concentrated in the high-tech district block, the northern Yanbei block and the northeastern platform area.

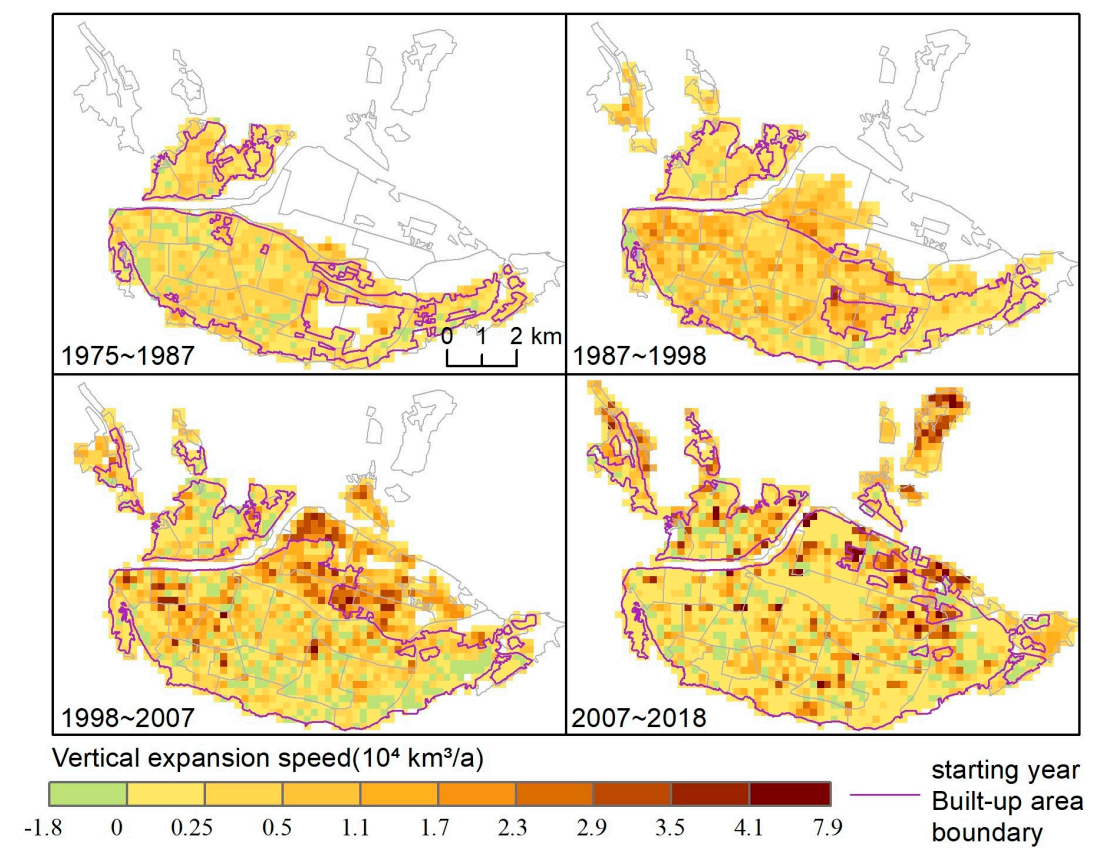

Figure 7. Vertical expansion speed change. 
We calculated the weighted average height and volume of buildings, and their height and volume change rate (Table 3). The weighted average height of the buildings was obtained by the ratio of the total volume of the buildings to the floor area of the buildings [22]. The results show that from 1975 to 2018, the height and volume of the Chengguan District continued to increase. The weighted average height of buildings increased from $6.12 \mathrm{~m}$ to $2.12 \mathrm{~m}$, an increase of 2.47 times, and the maximum height of buildings reached $285 \mathrm{~m}$ in 2018. The volume increased from $0.57 \times 10^{8} \mathrm{~m}^{3}$ to $3.26 \times 10^{8} \mathrm{~m}^{3}$, an increase of 4.7 times. The change rate of building height fluctuated but did not change much during $1975-2007$, while it quickly rose from $27.61 \%$ to $66.8 \%$ in $2007-2018$. The building volume change rate continued to rise during 1975-2018. It increased the fastest during the period 1998-2007 (increasing by $3.27 \times 10^{6} \mathrm{~m}^{3} /$ a from the previous period), and reached $10 \times 10^{6} \mathrm{~m}^{3} / \mathrm{a}$ in 2007-2018 (increasing by $1.63 \times 10^{6} \mathrm{~m}^{3} / \mathrm{a}$ from the previous period). Combined with the horizontal expansion change and the area change rate (Figure 2, Table 2), we used the area change rate of the built-up area and the change rate of the building height to characterize the horizontal and vertical expansion speed of the Chengguan area. It can be found that from 1975 to 2007, the horizontal expansion speed increased while the speed of vertical expansion remained relatively stable. From 1998 to 2007, the horizontal expansion speed reached its peak value, and the volume change rate also reached the maximum growth rate, indicating that the horizontal and vertical expansion greatly contributed to the three-dimensional expansion during this period. In 2007-2018, the horizontal expansion speed slowed down and the vertical expansion speed increased, and the volume change rate peaked, indicating that the vertical expansion dominated the urban expansion direction during this period.

Table 3. Weighted average height, volume, and rate of change of Chengguan buildings.

\begin{tabular}{cccccc}
\hline Year & $\mathbf{1 9 7 5}$ & $\mathbf{1 9 8 7}$ & $\mathbf{1 9 9 8}$ & $\mathbf{2 0 0 7}$ & $\mathbf{2 0 1 8}$ \\
\hline Weighted average height $(\mathrm{m})$ & 6.12 & 7.87 & 9.96 & 12.71 & 21.20 \\
\hline Weighted average height change rate $\%$ & 28.59 & & 26.56 & 27.61 & 66.80 \\
\hline Volume $\left(10^{8} \mathrm{~m}^{3}\right)$ & 0.57 & 0.84 & 1.41 & 2.16 & 3.26 \\
\hline Volume change rate $\left(10^{6} \mathrm{~m}^{3} / \mathrm{a}\right)$ & 2.28 & & 5.10 & 8.37 & 10.00 \\
\hline
\end{tabular}

\subsubsection{Changes in the Appearance of the City}

Skyline:

The skyline analysis (Figure 8) shows that the city skyline of Chengguan District had experienced a change from flat to single peak, double peak, and extreme value. The southwestern region developed faster than other regions, followed by the northern middle region. In 1975 and 1987, the height of urban buildings was low and the skyline was flat. The skyline dropped slightly from west to east and from south to north in 1975, and fluctuated slightly in the middle in both directions in 1987. The city skyline showed a peak phenomenon of west high-east low, south high-north low in 1998, indicating that the southwestern part of the city developed more. In 2007, the skyline showed a peak and sub-peak from west to east, a peak and sub-peak from south to north, a slight fluctuation in the east, and the height of the peak in the southwest was greater than that of the previous period. This shows that the middle part of the city was gradually developing but the development degree was not as good as that of the southwest. 


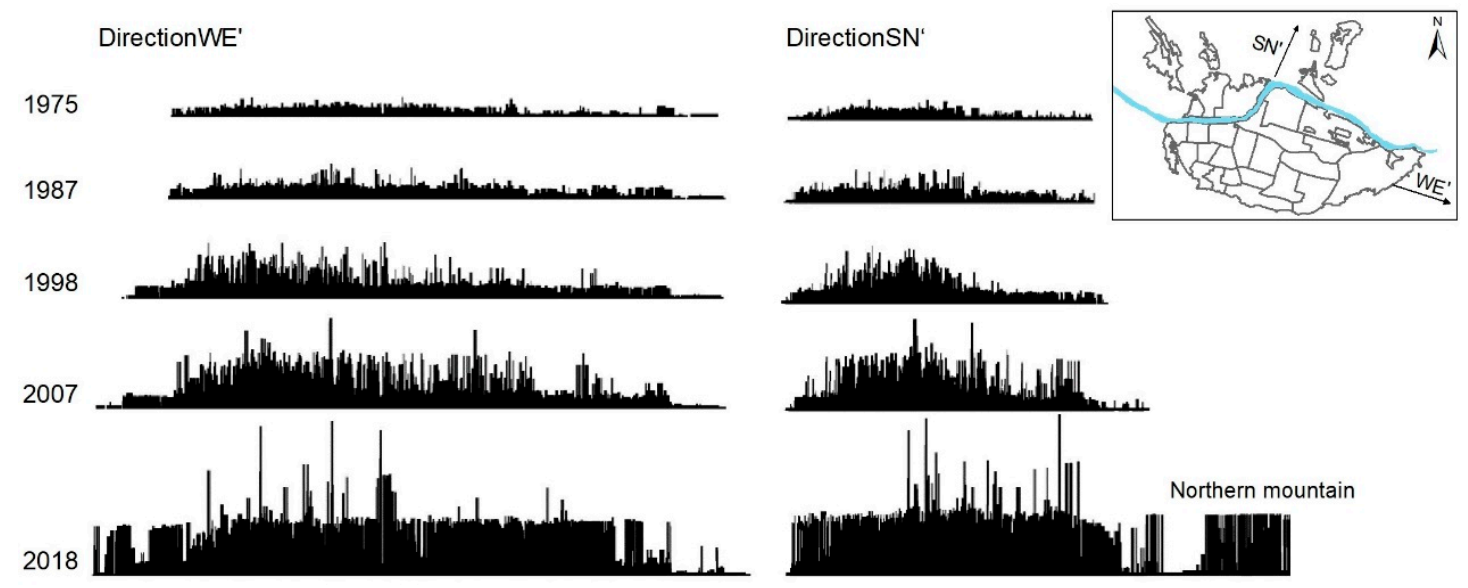

Figure 8. Skyline analysis from two directions.

Fluctuation degree:

We calculated the FD of the buildings in the calculation unit (Figure 9), and found that in 1975, the FD of the Chengguan District was generally low, and it was lower in the northern and southern edges of the built-up area. In 1987, the FD of the urban core area and the northern Yanchangbao area increased slightly, while the core area FD was higher. In 1998, the integral building height in the core area increased, causing a decline in FD, and the overall FD of the city became more consistent. In 2007, the heights of new buildings in the Yantan area and the Yanchang area were quite different, increasing the building FD. In 2018, except for the southwest, the FD in other areas of the built-up area became higher than before. This shows that, from 1975 to 2018, as the height of the building changed, the FD of the city's construction area rose first in the core area, and then rose faster in other areas outside the core area. The city image changed from the overall low building height and low FD to the core area high building height and low FD, while other areas had high building height and high FD.

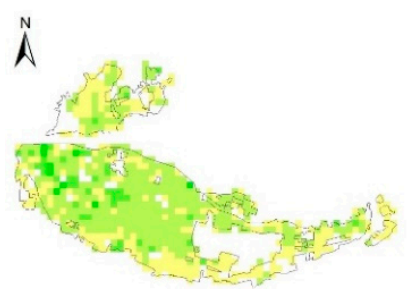

1975

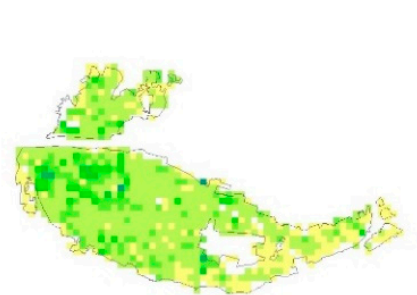

1987

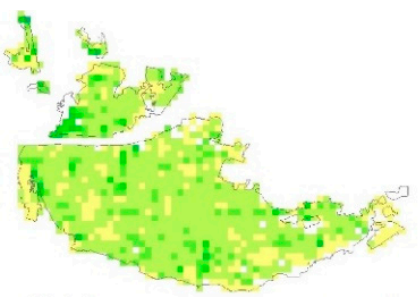

1998
Fluctuation degree

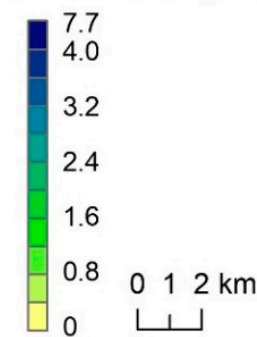

Figure 9. Changes in building fluctuation degree.

\section{Discussion}

\subsection{Factors Affecting the Three-Dimensional Expansion of Chengguan District}

It can be seen from the above analysis that the form, main direction and strength of the three-dimensional expansion of Chengguan District were different in different periods. According to 
existing research, these differences can be attributed to policy factors, population, economic growth factors, industrial restructuring factors, and natural factors such as topography [36,37].

Driven by policy factors, urban space development in Chengguan District has progressed in a piecewise pattern. Lanzhou City's Second Phase of Urban Planning (1978-2000) began with zoning the city from 1985, dividing Chengguan District into the Chengguan central area, the Yanchang area, the Donggang area and the Yantan township, which was planned separately. Chengguan Central area is bordered by the Gaolan Mountain in the south, Huanghe River in the north, Linxia Road block in the west, and Jiayuguan Road block in the east. It was planned to be the political, economic, cultural, and scientific research center of Lanzhou City, and the renovation of its old city has also been clearly planned. The Yanchang area is located across the river from the Chengguan Central area, it was planned as a local industrial area and a living and residential area. The Donggang area starts from Jiayuguan Road block in the west and reaches the Lanzhou Valley exit in the east, north to the tributary of the Yellow River in the south of the city, and south to the north of the Gaolan Mountain, which is an important hub connecting Lanzhou City to Longxi, Guanzhong, and the eastern part of China. It was planned as a comprehensive economic zone for material exchange, warehousing, transit and wholesale to other regions. Yantan township is bordered by the Yellow River in the north and Donggang District in the south. It has a low terrain and was originally a floodplain of the Yellow River. People built dams and reclaimed land, due to its fertile soil, Yantan township became an important base for fruit and vegetables of Lanzhou. The Third Phase of Urban Planning (2000-2010) made group planning for the Chengguan central area, Donggang area, Yantan area, and Yanchang area, respectively. The development of the Lanzhou high-tech industrial development zone in the Yantan Area, which was approved in 1991, became the main reason for guiding the eastward expansion of the Chengguan District during in this period. That is, Yantan township was gradually reducing the planning restrictions on agricultural land. It turned from a melon and fruit vegetable base to a high-tech industrial park where a large number of residential lands have replaced agricultural land. At the same time, planning restrictions on the barren hills have been relaxed, the Jiuzhou economic development zone in the northwest of the Jiuzhou area also promoted the expansion of the city. The Fourth Phase of Urban Planning (2010-2020) strengthened the northern mountain development and strictly controlled the construction of the southern mountain. Therefore, the Lanzhou Country Garden residential area was gradually completed in the Baidaoping area in the northern mountain area. Besides, the industrial structure of Donggang District has undergone a major change, it has turned from industrial areas to integrated logistics parks and residential areas. However, the implementation of urban planning was more about grasping the direction of urban development in functional planning. In the actual implementation process, Lanzhou urban development is more affected by the changes in the economic system after China's reform and opening-up, the adjustment of state-owned enterprises, economic structure, industrial structure, and housing system reform. The population and the development of various industries far exceeded the expectations of the plan.

Population and economy are the endogenous driving forces for the development of the city. From 1975 to 1987, the population of Chengguan District increased from 431,200 to 586,000, an increase of about 154,000 people; in 1998, it reached 753,000, an increase of about 167,000 people; in 2007, it reached 982,500, an increase of about 229,500 people; in 2018, it reached 1.316 million, an increase of about 333,500 people. Correspondingly, the horizontal expansion of Chengguan District in 1975-2007 shifted from low speed to high speed, and in 2007-2018 the vertical expansion accelerated rapidly while the horizontal expansion slowed down. The GDP of Chengguan District increased from 9.19 billion yuan in 1998 to 26.2 billion yuan in 2007, reaching 94.889 billion yuan in 2018, which is 10.3 times that of 1998. In 2009, Yixing Zhou [38] found that economic growth has a logarithmic relationship with urban expansion. In 2018, Some studies [21] discovered that during rapid economic growth, limited space availability, and slow population growth, several megacities in Asia have experienced very slow horizontal growth, but still grew vertically. This is similar to what we found in Chengguan District. In the case of limited horizontal space expansion and continuous population growth, the horizontal 
expansion speed of the Chengguan District has slowed down, while the speed of vertical expansion has increased rapidly. This shows that with rapid economic development, its impact on urban horizontal expansion is gradually weakened, while the impact on vertical expansion is still obvious.

Industrial restructuring has affected the vertical expansion of the city. From 1975 to 1987, the interior of the old city was mainly devoted to residential areas, and construction projects mainly dealt with maintenance. Therefore, many multi-buildings were built around the old city, and vertical expansion was limited (Figure 7). After the policy reform, a large number of construction projects of administrative offices, financial commerce, cultural education, science and technology, and residences were carried out in the old city to build the Lanzhou Administrative Economic Center. Therefore, the built-up area becomes gradually dominated by mid and high-rise buildings (Figure 4). Ultra-high-rise buildings, such as the $139 \mathrm{~m}$ China-Hungary Friendship Building and the $285 \mathrm{~m}$ Hongyun Jinmao Tower, begin to appear. The speed of vertical expansion was very fast, forming a peak of aggregation. Driven by the development of the high-tech industrial development zones, agricultural and agricultural by-product preservation, food processing and transportation, and commercial and trade wholesale markets, the Yantan Area evolves from an agricultural to a comprehensive economic development zone, supporting the development of high-rise office buildings and residential communities, forming the sub-peak of urban development. The Donggang area mainly develops material turnover, wholesale, storage, and transportation due to its advantageous location. While its early buildings are not high, the development of residential quarters has driven it to rapid vertical growth in recent years.

Topographical factors play a limiting role in the horizontal expansion of the Chengguan District. Although the development of Yantan area, Jiuzhoutai area, and Baidaoping area are a manifestation of humans overcoming topographical factors, the north and south mountains bordering the city are still the biggest limiting factors for urban development. In 2007-2018, urban construction development guided Chengguan District to growth vertically. On the other hand, the contradiction between population, economic growth, and terrain constraints was also an important factor leading to the sharp vertical expansion of the city.

\subsection{Three-Dimensional Expansion and Existing Problems in Chengguan District}

As a typical space-limited river valley city, Lanzhou Chengguan District has a very different development pattern from plain cities. In the horizontal expansion direction, it distinguishes itself from the typical concentric circular growth pattern $[39,40]$, and developed in a piecewise pattern. In the vertical direction, it is different from the classic shape of "high center, low periphery" [21,27], showing a bimodal urban form. We also found that, in recent years, new construction in Chengguan District consisted more often in high-rise buildings taller than $50 \mathrm{~m}$ instead of small high-rise buildings of 30-50 m. Similarly to the development in Beijing [28], higher buildings were more efficient at meeting the need of accelerated population growth, and enhanced human comfort by reducing building density, reducing surface temperature, and improving the greening of the environment. However, this phenomenon also reflects the large population density in Chengguan District.

The urban development model of Chengguan District is similar to the alternating form of horizontal expansion and vertical expansion found in Greece [18]. The horizontal expansion proceeded rapidly in the early stages, and then was overcome by an increase in vertical expansion. Due to the limitation of the river valley terrain, the urban areas expanded vertically very fast in 2007-2018. Furthermore, the relationship between the height of the building and the space required in the horizontal direction of the building makes it impossible to increase the height of the building without limitation. Therefore, the horizontal expansion in the mountain reclamation area has occurred in the North Mountain. There are many gentle hillside development pilot zones in the North Mountain that were planned in the fourth edition of Lanzhou urban planning (2010-2020). It is conceivable that Lanzhou City and Chengguan District will experience a large horizontal expansion. However, mountains in the north and south of Lanzhou are mostly loess hilly landforms formed by denudation and accumulation, and are higher than the inner plains of the valley. Although mountain reclamation can alleviate the pressure of 
urban population growth, it brings about the consequences of urban soil erosion, increased dust, and ecological deterioration, impeding the sustainable development of the city. Therefore, the expansion of mountain reclamation in Lanzhou City cannot be carried out on a large scale. It is necessary to be cautious and careful in the arrangement of time and space. Vertical expansion still plays an important role in urban development, reasonable vertical expansion can improve land use efficiency and improve people's quality of life. There are many similar valley-type cities in China facing the same dilemma. Our findings could provide new insights and methods into assessing the extent of urban development and identifying areas with potential vertical expansion, and could also provide an indication of whether the saturation of the urban central development affects the comfort of human habitations.

\section{Conclusions}

With Chengguan District of Lanzhou as the study area, we analyzed four decades of three-dimensional expansion of the city from 1975-2018. The main conclusions are as follows: (1) Urban horizontal expansion of Chengguan district took place gradually from low-altitude to high-altitude mountain areas, the expansion mode shifted from adjacent-type to enclave-type, the expansion speed increased in 1975-2007, and declined in 2007-2018. (2) Building height was first higher in the surroundings of the core area, lower in core area, and then higher in the core area, and lower outwards. The main types of new buildings changed from multi-story buildings to high-rise buildings with a height greater than $50 \mathrm{~m}$, and from 2007 to 2018, the proportion of new high-rise buildings taller than $50 \mathrm{~m}$ reached $81.1 \%$. Building density and floor area ratio was highest in the core area. (3) Vertical expansion initially occurred in the urban core area where the horizontal expansion was complete, later tended to take place simultaneously with horizontal expansion, and still continued where horizontal expansion ended. The vertical expansion speed was relatively stable when the horizontal expansion speed increased rapidly in 1975-2007, and then increased rapidly when horizontal expansion decreased quickly in 2007-2018. (4) The city skyline gradually changed from flat to single peak, double peak and extreme value. The peak showed that the center position of the core area remained unchanged, but its fluctuation degree was relatively low, and the northeast and southeast margins of the built-up area were relatively high. The results of our study could provide a reference for the sustainable development planning and policy formulation of valley-type cities like Lanzhou. However, due to limitations related to data accessibility, the use of manual visual interpretation was characterized by a degree of subjectivity, which might cause errors of interpretation and further improvements are needed in the future.

Author Contributions: Conceptualization, S.H.; methodology, S.H.; software, S.H.; validation, S.H.; formal analysis, S.H.; investigation, S.H.; resources, S.H. and Y.X.; data curation, S.H; writing-original draft preparation, S.H.; writing-review and editing, S.H., J.D., Y.X., B.W., J.J., H.D. and X.W.; supervision, S.H, Y.X. and J.J.; project administration, S.H, Y.X. and J.J.; funding acquisition, Y.X. and J.J.

Funding: The National Natural Science Foundation of China [No. 41530752, 41471163 and 41601064], the Technology Basic Resource Investigation Program of China [No. 2017FY101003] and the Strategic Priority Research Program of Chinese Academy of Sciences, Pan-Third Pole Environment Study for a Green Silk Road (Pan-TPE) [No. XDA2009000001] and the Fundamental Research Funds for the Central Universities [No. 561219050].

Conflicts of Interest: The authors declare no conflict of interest.

\section{References}

1. Sarvestani, M.S.; Ibrahim, A.L.; Kanaroglou, P. Three decades of urban growth in the city of Shiraz, Iran: A remote sensing and geographic information systems application. Cities 2011, 28, 320-329. [CrossRef]

2. Koziatek, O.; Dragićević, S. iCity 3D: A geosimualtion method and tool for three-dimensional modeling of vertical urban development. Landsc. Urban. Plan. 2017, 167, 356-367. [CrossRef]

3. Chung, U.; Choi, J.; Yun, J.I. Urbanization effect on the observed change in mean monthly temperatures between 1951-1980 and 1971-2000 in Korea. Clim. Chang. 2004, 66, 127-136. [CrossRef]

4. Fan, P.; Xie, Y.; Qi, J.; Chen, J.; Huang, H. Vulnerability of a coupled natural and human system in a changing environment: Dynamics of Lanzhou's urban landscape. Landsc. Ecol. 2014, 29, 1709-1723. [CrossRef] 
5. Seto, K.C.; Burak, G.; Hutyra, L.R. Global forecasts of urban expansion to 2030 and direct impacts on biodiversity and carbon pools. Proc. Natl. Acad. Sci. USA 2012, 109, 16083-16088. [CrossRef]

6. Han, L.; Zhou, W.; Li, W. Increasing impact of urban fine particles (PM2.5) on areas surrounding Chinese cities. Sci. Rep. 2015, 5, 12467. [CrossRef]

7. Zhou, W.; Jia, W.; Cadenasso, M.L. Effects of the spatial configuration of trees on urban heat mitigation: A comparative study. Remote Sens. Environ. 2017, 195, 1-12. [CrossRef]

8. Li, B.; Liu, Z.; Nan, Y.; Li, S.; Yang, Y. Comparative analysis of urban heat island intensities in Chinese, Russian, and DPRK regions across the transnational urban agglomeration of the Tumen river in northeast Asia. Sustainability 2018, 10, 2637. [CrossRef]

9. Galster, G.; Hanson, R.; Ratcliffe, M.R.; Wolman, H.; Coleman, S.; Freihage, J. Wrestling sprawl to the ground: Defining and measuring an elusive concept. Hous. Policy Debate 2001, 12, 681-717. [CrossRef]

10. Frolking, S.; Milliman, T.; Seto, K.C.; Friedl, M.A. A global fingerprint of macro-scale changes in urban structure from 1999 to 2009. Environ. Res. Lett. 2013, 8, 024004. [CrossRef]

11. Fan, C.C. The vertical and horizontal expansions of China's city system. Urban. Geogr. 1995, 20, 493-515. [CrossRef]

12. Long, Y.; Gu, Y.; Han, H. Spatiotemporal heterogeneity of urban planning implementation effectiveness: Evidence from five urban master plans of Beijing. Landsc. Urban. Plan. 2012, 108, 103-111. [CrossRef]

13. Deng, F.F.; Huang, Y. Uneven land reform and urban sprawl in China: The case of Beijing. Prog. Plan. 2004, 61, 211-236. [CrossRef]

14. Bagan, H.; Yamagata, Y. Land-cover change analysis in 50 global cities by using a combination of Landsat data and analysis of grid cells. Environ. Res. Lett. 2014, 9, 064015. [CrossRef]

15. Batty, M.; Besussi, E.; Maat, K.; Harts, J.J. Representing multifunctional cities: Density and diversity in space and time. Built Environ. 2004, 30, 324-337. [CrossRef]

16. Silva, P.; Li, L. Mapping urban expansion and exploring its driving forces in the city of Praia, Cape Verde, from 1969 to 2015. Sustainability 2017, 9, 1434. [CrossRef]

17. Kityuttachai, K.; Tripathi, N.; Tipdecho, T.; Shrestha, R. CA-Markov analysis of constrained coastal urban growth modeling: Hua Hin seaside city, Thailand. Sustainability 2013, 5, 1480-1500. [CrossRef]

18. Zambon, I.; Colantoni, A.; Salvati, L. Horizontal vs. vertical growth: Understanding latent patterns of urban expansion in large metropolitan regions. Sci. Total Environ. 2019, 654, 778-785. [CrossRef]

19. Zhang, P. Spatiotemporal Features of the three-dimensional architectural landscape in Qingdao, China. PloS ONE 2015, 10, e0137853. [CrossRef]

20. Zhang, W.; Li, W.; Zhang, C.; Ouimet, W.B. Detecting horizontal and vertical urban growth from medium resolution imagery and its relationships with major socioeconomic factors. Int. J. Remote Sens. 2017, 38, 3704-3734. [CrossRef]

21. Zhang, W.; Li, W.; Zhang, C.; Hanink, D.M.; Liu, Y.; Zhai, R. Analyzing horizontal and vertical urban expansions in three East Asian megacities with the SS-coMCRF model. Landsc. Urban. Plan. 2018, 177, 114-127. [CrossRef]

22. Qin, J.; Fang, C.; Wang, Y.; Li, G.; Wang, S. Evaluation of three-dimensional urban expansion: A case study of Yangzhou City, Jiangsu Province, China. Chin. Geogr. Sci 2014, 25, 224-236. [CrossRef]

23. Soergel, U.; Michaelsen, E.; Thiele, A.; Cadario, E.; Thoennessen, U. Stereo analysis of high-resolution SAR images for building height estimation in cases of orthogonal aspect directions. ISPRS J. Photogramm. Remote Sens. 2009, 64, 490-500. [CrossRef]

24. Sportouche, H.; Tupin, F.; Denise, L. Extraction and three-dimensional reconstruction of isolated buildings in urban scenes from high-resolution optical and SAR spaceborne images. IEEE Trans. Geosci. Remote Sens. 2011, 49, 3932-3946. [CrossRef]

25. Zhao, Z.; Duan, Y.; Zhang, Y.; Cao, R. Extracting buildings from and regularizing boundaries in airborne lidar data using connected operators. Int. J. Remote Sens. 2016, 37, 889-912. [CrossRef]

26. Handayani, H.; Murayama, Y.; Ranagalage, M.; Liu, F.; Dissanayake, D. Geospatial Analysis of horizontal and vertical urban expansion using multi-spatial resolution data: A case study of Surabaya, Indonesia. Remote Sens. 2018, 10, 1599. [CrossRef]

27. Shi, L.; Shao, G.; Cui, S.; Li, X.; Lin, T.; Yin, K.; Zhao, J. Urban three-dimensional expansion and its driving forces-A case study of Shanghai, China. Chin. Geogr. Sci. 2009, 19, 291-298. [CrossRef] 
28. Zheng, Z.; Zhou, W.; Wang, J.; Hu, X.; Qian, Y. Sixty-year changes in residential landscapes in Beijing: A perspective from both the horizontal (2D) and vertical (3D) dimensions. Remote Sens. 2017, 9, 992. [CrossRef]

29. He, Q.; Liu, Y.; Chen, Z.; Yin, C.; Tan, R. Simultaneously simulate vertical and horizontal expansions of a future urban landscape: A case study in Wuhan, Central China. Int. J. Geogr. Inf. Sci. 2017, 31, 1-22. [CrossRef]

30. Zhang, P. Spatial fluctuation of urban architecture. J. Arid Land Resour. Environ. 2016, 30, 51-57.

31. Anjuke. Available online: http://www.anjuke.com/ (accessed on 7 March 2019).

32. China National Standards. Residential Building Code (GB50368-2005); China Architecture \& Building Press: Beijing, China, 2005.

33. China National Standards. Code for Design of Civil. Building (GB50352-2005); China Architecture \& Building Press: Beijing, China, 2005.

34. Scott, D.W. Multivariate Density Estimation: Theory, Practice, and Visualization; John Wiley \& Sons: Hoboken, NJ, USA, 2015.

35. Qiao, W.; Liu, Y.; Wang, Y.; Yuying, L.U. Analysis on the characteristics of three-dimensional urban space expansion in Nanjing since 2000. Geogr. Res. 2015, 34, 666-667.

36. Liu, S.H.; Shen, Y.F. A probe into the urban sprawl model and its drive mechanism in Shanghai. Econ. Geogr. 2006, 26, 487-491. [CrossRef]

37. Moreira, F.; Rego, F.C.; Ferreira, P.G. Temporal (1958-1995) pattern of change in a cultural landscape of northwestern Portugal: Implications for fire occurrence. Landsc. Ecol. 2001, 16, 557-567. [CrossRef]

38. Yixing, Z. On the relationship between urbanization and gross national product. Chin. Sociol. Anthropol. 1988, 21, 3-16. [CrossRef]

39. Peng, W.; Wang, G.; Zhou, J.; Zhao, J.; Yang, C. Studies on the temporal and spatial variations of urban expansion in Chengdu, western China, from 1978 to 2010. Sustain. Cities Soc. 2015, 17, 141-150. [CrossRef]

40. Taubenböck, H.; Wiesner, M.; Felbier, A.; Marconcini, M.; Esch, T.; Dech, S. New dimensions of urban landscapes: The spatio-temporal evolution from a polynuclei area to a mega-region based on remote sensing data. Appl. Geogr. 2014, 47, 137-153. [CrossRef]

(C) 2019 by the authors. Licensee MDPI, Basel, Switzerland. This article is an open access article distributed under the terms and conditions of the Creative Commons Attribution (CC BY) license (http://creativecommons.org/licenses/by/4.0/). 